\title{
Brincando de bonecos: um ensaio benjaminiano sobre mimesis
}

\section{Playing with dolls: a Benjaminian essay on mimesis}

\author{
John C. Dawsey ${ }^{*}$ \\ * Universidade de São Paulo - São Paulo, SP, Brasil \\ johndaws@usp.br \\ https://orcid.org/0000-0003-1427-7804
}

Claudia da Silva Santana**

** Universidade Metodista de Piracicaba - Piracicaba, SP, Brasil cssantan@yahoo.com.br https://orcid.org/0000-0001-9371-1669 


\title{
Resumo
}

Neste ensaio de inspiração benjaminiana se discute um circuito mimético em que bonecos criados à semelhança de "velhos barranqueiros" entram em relações com moradores que se tornam semelhantes aos bonecos. O gesto de um artesão de povoar as margens de um rio retorna com a força de um campo energizado por bonecos e moradores revitalizando os últimos em sua determinação de não saírem de suas moradas. Imagens de antepassados que fizeram suas moradas às margens do rio Piracicaba e de índios paiaguás ou evuevi - "gente do rio" - se articulam ao presente, num momento de perigo, em que moradores se veem ameaçados por um projeto da prefeitura de "reconquista da Rua do Porto" associado à restauração de um imaginário bandeirante. Chama atenção o modo como os resíduos da cidade e da sua história, coletados por um artesão numa carroça puxada por um cavalo chamado Lontra, ganham vida na forma dos bonecos.

Palavras-chave: bonecos; imagens de semelhança; circuito mimético benjaminiano; circuito da dádiva.

\begin{abstract}
This essay proposes to discuss, from a Benjaminian perspective, a mimetic circuit in which dolls that are similar to ancestral riverbank dwellers enter into relations with people living on the banks of the river, who become similar to dolls. The gesture of an artisan to populate the banks of a river returns with the force of a field which is energized by dolls and riverbank dwellers, invigorating the latter in their determination not to be removed from their homes. Images of people from the past who made their homes and fished from the banks of the Piracicaba River and of Amerindian Paiaguá or evuevi "river people" articulate with the present in a moment of danger in which dwellers are threatened by a city government project of "reconquest of Riverbank Street" associated with the restoration of a bandeirante (backland explorer and Indian slave-hunter) heroic imaginary. Attention is called to the way in which residues of the city and its history, collected by an artisan in a cart pulled by a horse named Otter, come to life in the form of riverine dolls.
\end{abstract}

Keywords: dolls; images of the similar; Benjaminian mimetic circuit; gift circuit. 


\section{Introdução ${ }^{1}$}

Nos anos 1970 surgiram os primeiros bonecos à beira do rio Piracicaba. Eram bonecos pescadores, caipiras (ver Figura 1). Se essas figuras às vezes eram chamadas de "bonecos do Elias", o artista e artesão Elias Rocha, invertendo e corrigindo a formulação, chamava a si mesmo de "Elias dos bonecos". Elias era um "barranqueiro", nascido e criado nas margens do rio. Os bonecos surgiram ao lado da Casa do Povoador, considerada a mais antiga casa de Piracicaba (SP). No imaginário popular essa casa teria pertencido ao herói fundador da cidade, o bandeirante Capitão Antônio Corrêa Barbosa. Na época em que os bonecos fizeram as sua primeiras aparições, a prefeitura restaurava a Casa do Povoador. Também nessa época, ela dava início ao projeto de "reconquista da Rua do Porto", que envolvia - além das obras de restauração - a promoção do turismo, a urbanização da principal rua beirando o rio, a construção da nova sede da prefeitura e a remoção de moradores.

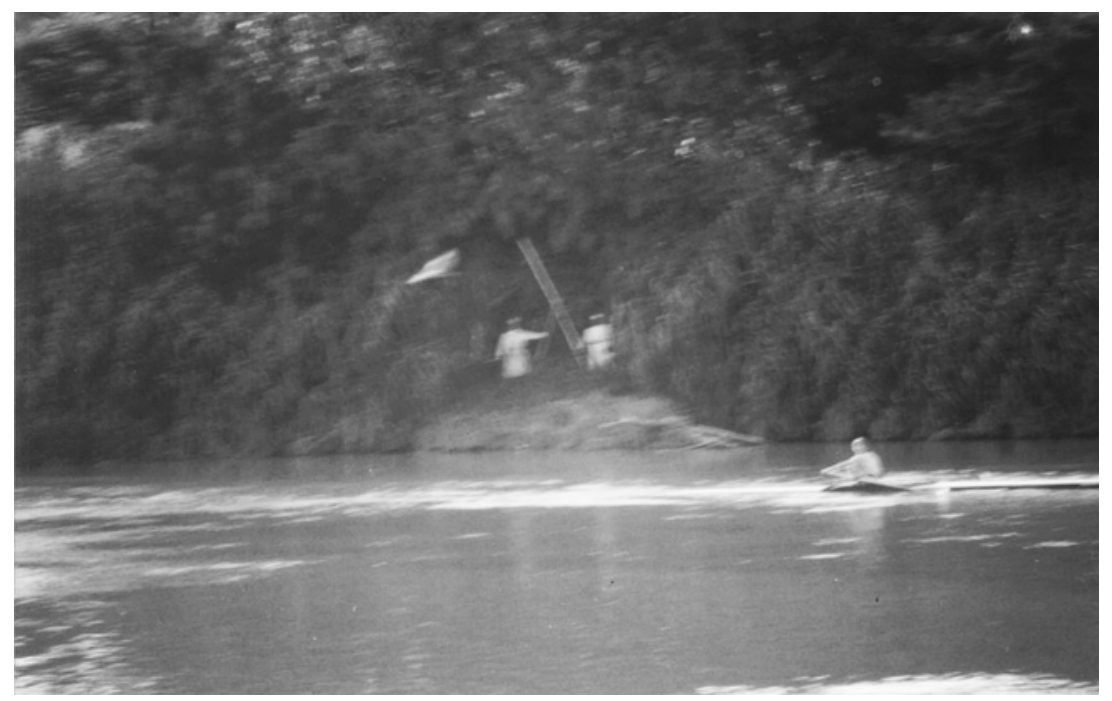

Figura 1. Bonecos. Foto: John C. Dawsey.

1 A pesquisa de John C. Dawsey para este ensaio foi financiada pela Fapesp - Fundação de Amparo à Pesquisa do Estado de São Paulo (Fapesp 2018/19609-9) - e pelo CNPq - Conselho Nacional de Desenvolvimento Científico e Tecnológico (CNPq - PQ 310884/2015-2). 
Em dois textos curtos, "Doutrina das semelhanças" e "Sobre a capacidade mimética", ambos escritos em 1933, Walter Benjamin discute a noção de mimesis. ${ }^{2}$ Trata-se de uma capacidade de reconhecer e produzir semelhanças. Na abertura para o outro o dom de tornar-se semelhante produz um saber. As semelhanças percebidas conscientemente - por exemplo, quando olhamos para um rosto - são significativas. Mas há uma infinidade de semelhanças de que não temos consciência. Para os povos antigos, diz Benjamin, o gênio mimético foi visto como uma força decisiva, sendo associado ao ato de criação e ao nascimento do ser. Tinha a ver com o ajustamento à ordem do cosmos. Ao longo do processo civilizatório, porém, ocorreram transformações profundas. O dom da capacidade mimética tem uma história. Observa-se uma crescente fragilidade desse modo de se relacionar com o universo. Hoje, a capacidade de reconhecer e produzir semelhanças se refugia nas artes, na linguagem, na escrita e, de modo fulgurante, nas brincadeiras de crianças. As crianças, diz Benjamin (1985b, p. 108), "brincam não apenas de comerciante ou professor, também brincam de trem e moinho de vento". ${ }^{3}$ À beira do rio Piracicaba, Elias brinca de bonecos.

Tudo começou, de acordo com Elias, com a filha de uma vizinha que queria um boneco. Já havendo feito bonecos para as festas de malhação de Judas na Rua do Porto, Elias fez um boneco para a criança. A menina gostou. Mas o seu irmão mais novo se assustou. Não conseguia dormir com o boneco em casa. A mãe das crianças então pediu que Elias levasse o boneco embora. Ele o levou para a beira do rio. Ao colocar o boneco no barranco, o próprio Elias se assustou, pois, na imagem do boneco, ele reconheceu as pessoas de sua própria família e vizinhança, inclusive as que haviam falecido (ver Figuras 2 e 3 ). Eram os "velhos barranqueiros", pessoas como ele que nasceram e viveram à beira do rio. Outros bonecos feitos por Elias logo se juntaram ao primeiro. De início foram colocados ao lado da Casa do Povoador.

2 "A doutrina das semelhanças" (Benjamin, 1985b, 1999a), escrito entre janeiro e fevereiro de 1933, constitui uma primeira versão do texto ainda mais curto, "Sobre a capacidade mimética" (Benjamin, 1999b), escrito entre abril e setembro do mesmo ano.

3 Também em Benjamin (1999a, p. 694, 1999b, p. 720). 


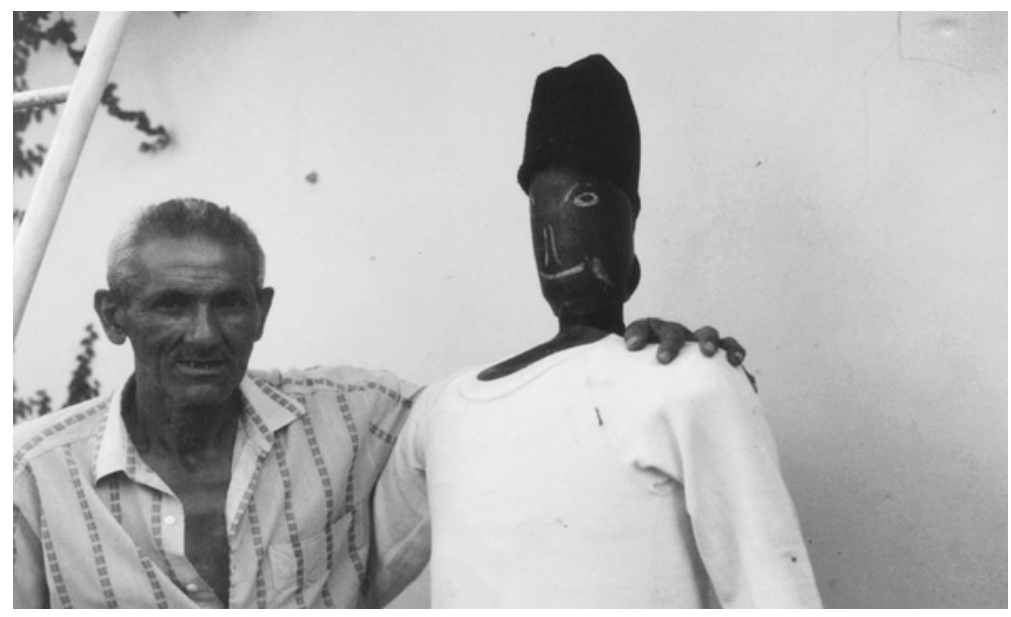

Figura 2. Elias Rocha e boneco. Foto: John C. Dawsey.

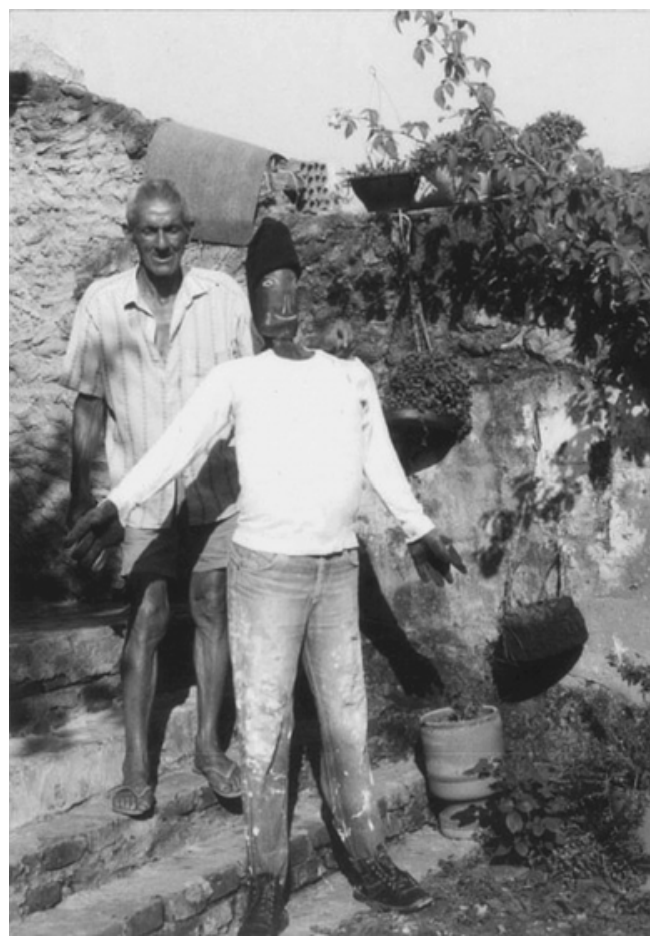

Figura 3. Elias Rocha e boneco. Foto: John C. Dawsey. 
Como demonstra Jeanne-Marie Gagnebin (1993), há tempos a noção de mimesis vem sendo combatida. Platão detectou na imagem mimética uma força de arrebatamento, mas também um fator de engano e ilusão. No século passado, Adorno e Horkheimer (1969) retomaram a crítica platônica da passividade do sujeito na mimesis e chamaram atenção para a sua natureza regressiva. No ímpeto de querer ser outro, a demonstração da vontade de um apagamento de si. Em "Além do princípio do prazer", Freud (1961) viu na mimesis uma pulsão da morte, um desejo de dissolução do sujeito no nada. Outros autores, como Caillois e Mauss, analisaram o comportamento mimético como uma forma de assimilação ao perigo envolvendo uma espécie de esquiva ou desaparecimento.

Walter Benjamin, porém, retoma uma vertente aristotélica de análise. Em contraponto ao seu mestre Platão, Aristóteles ressalta os aspectos positivos da mimesis, entendendo-a como uma forma humana privilegiada de aprendizado. Ele indaga sobre a capacidade mimética do ser humano. Na mimesis se encontra um componente ativo e criativo - o reconhecimento de semelhanças. A sua raiz é lúdica e artística.

Benjamin (1985a) também se inspira em Marcel Proust. Imagens do passado irrompem no presente dos fundos do esquecimento. Num instante, a partir de um reconhecimento de semelhanças, relampeiam. Em Proust e Freud, Benjamin (1995) descobre a força do conceito de memória involuntária. No ato voluntário e consciente de produzir uma lembrança e de narrar o que foi lembrado, se produz o esquecimento. No contar de uma história, as atenções se voltam ao suprimido. Na audição de uma narrativa, elas se dirigem às elipses, aos lapsos, às incoerências e emendas suspeitas. Em momentos de perigo, das camadas mais profundas da memória involuntária, afloram imagens vitais.

O pensamento benjaminiano também leva as marcas da noção de correspondances de Baudelaire (Benjamin, 1995). No entrecruzamento de tempos, se detectam correspondências. De modo constelacional se configuram relações entre as imagens. Friccionando o presente, ressurge o passado diferente de si mesmo e, no entanto, semelhante. Passado e presente entram em relações de semelhança, explodindo, como diz Benjamin (1985d), o continuum do tempo.

Em outro ensaio (Dawsey, 2012), John procurou focar a memória involuntária e sua importância para a reformulação de uma antropologia da experiência e da performance. Nesse registro, Elias Rocha se revela como um narrador. 
Como um desdobramento surpreendente, embora secundário, surgiu uma ideia incipiente de circuito mimético. No presente ensaio, essa ideia ganha força. $O$ presente ensaio se unifica e se ordena em torno do conceito benjaminiano de mimesis. A seguir, a noção de um circuito mimético é pensada em uma dimensão temporal e histórica, envolvendo imagens do passado e do presente. Num registro benjaminiano da mimesis, também será discutido um circuito da dádiva, com obrigações de dar, receber e retribuir. Nesse caso, trata-se de um conjunto de relações de semelhança e dádiva entre vivos e mortos, entre moradores que vivem atualmente em áreas adjacentes ao rio e bonecos vistos como uma fulguração de antepassados. Em Mimesis and alterity, de inspiração benjaminiana, Michael Taussig (1993) também encontra indícios sugestivos de afinidades entre relações de mimesis e dádiva.

A seguir, a mimesis se apresenta de diferentes modos no texto, tanto como objeto de análise quanto como recurso analítico. Em foco, a ação mimética de Elias Rocha que ocorre na fabricação de bonecos. O conceito benjaminiano de mimesis constitui um recurso importante para analisar essa manifestação. Observa-se a intencionalidade de Elias. De início, a semelhança dos bonecos com antepassados surpreende o próprio artesão. Daí a importância da noção de memória involuntária que se associa ao conceito benjaminiano de mimesis. E a constatação de que ele, o artesão, seria o "Elias dos bonecos" e não o contrário. Num lampejo, no reconhecimento de uma semelhança, bonecos se revelam como pessoas, algumas já falecidas, que agem sobre o artesão. Porém, a partir do reconhecimento surpreendente inicial, a produção de semelhanças por meio da fabricação de bonecos, guiada por um "arcanjo divino", como será visto, passa a ser intencional.

Este ensaio surge como o efeito retardado de um susto, não apenas, como dito no início, da criança diante do boneco do artesão, ou do próprio Elias diante do mesmo artefato visto no barranco do rio, mas de um susto que um dos autores levou. Em fins dos anos 1970, em Piracicaba, uma cidade do interior do estado de São Paulo, no final do dia, andando em direção à Rua do Porto, ao passar pela Casa do Povoador, John olhou para "o lado de lá" do rio, a sua margem direita. Em meio à mata, nos barrancos, viu os bonecos. Imagens fantasmagóricas. Pareciam visagens. Depois soube o nome do artesão. Reviveu esse leve susto em duas ocasiões, em 1982 e 1989, quando retornou à cidade. No período de 1982 a 1985, realizou pesquisa de campo com boias-frias da região. Em 1993, 
pensando na possibilidade de realizar uma pesquisa sobre os bonecos, conversou com Elias no quintal de sua casa, próxima ao Largo dos Pescadores. Ali, o artesão vestia um dos bonecos. Dois já estavam prontos - um casal, homem e mulher. John pediu licença para gravar uma entrevista. Dessas conversas foi produzido um acervo de narrativas e informações. Elias Rocha era um narrador. Em 1993, ele gaguejava. Em 1996, depois de uma cirurgia, perdeu a voz. Mas anotava palavras em papel. Nos anos 1990, John também realizou entrevistas com outros moradores da Rua do Porto, alguns dos quais são mencionados neste ensaio. Trata-se de uma pesquisa inacabada. Não reuniu condições de realizar uma etnografia ao estilo de um Malinowski, residindo na Rua do Porto e acompanhando os movimentos cotidianos de bonecos e moradores, como pretendia. Também não encontrou alguns dados importantes, tais como o número de moradores desalojados pelo projeto de "reconquista da Rua do Porto" e o seu destino. Mesmo assim, ouviu relatos de moradores, reuniu informações de jornais da cidade, e buscou dados do Instituto Histórico e Geográfico de Piracicaba e dos órgãos da prefeitura local, com destaque ao IPPLAP - o Instituto de Pesquisas e Planejamento de Piracicaba.

\section{Casa do Povoador}

Os bonecos surgem de início em lugares próximos à Casa do Povoador. Em 1945 , a antiga casa, situada na margem do rio, foi adquirida pela prefeitura e, em 1967, na comemoração dos 200 anos de Piracicaba, foi reconhecida como símbolo da cidade. Foi tombada em 1969 como Monumento Histórico do Estado de São Paulo e restaurada, após longo processo, em 1986 (Cachioni; Grigoleto, 2011, p. 11). Em fins dos anos 1970, intensificaram-se as iniciativas de transformação da área da Rua do Porto, e a preservação da memória da cidade (Otero; Bologna; Almeida, 2011). A Casa do Povoador evoca as origens da cidade e chama atenção para a figura lendária do herói "povoador", o bandeirante Antônio Corrêa Barbosa. Ao longo do processo de restauração, um verdadeiro povoamento se insinua às margens de alguns dos monumentos: a multiplicação dos bonecos confeccionados por Elias Rocha.

As ações de preservação de memória não deixam de produzir semelhanças entre passado e presente, entre a imagem de um herói civilizatório e a de 
uma prefeitura que se apresenta como um bandeirante redivivo. A imagem do bandeirante impulsiona as ações da prefeitura. Em 1972, deu-se início à chamada "reconquista da Rua do Porto" e a um processo de desapropriação da vasta área de 23 hectares à margem esquerda do rio, adjacente à Casa do Povoador. Antigos moradores da beira do rio foram desalojados, perderam as suas moradas. Em fins dos anos 1970, ocorreram as primeiras iniciativas para transformar um brejo - onde, em sua infância, o fazedor de bonecos Elias caçava rãs - no atual Parque da Rua do Porto. Em 1988, com uma visão panorâmica para o Parque da Rua do Porto, foi inaugurada, na Rua Antônio Corrêa Barbosa, a nova sede da prefeitura: um edifício de dez andares, com heliponto, vidros espelhados e elevador externo para acesso direto ao gabinete do prefeito. A Rua do Porto, que era uma rua estreita de terra, foi pavimentada. Em fins de 1980, virou calçadão. Com a valorização da área, pressões aumentaram para que moradores vendessem as suas casas. Algumas, restauradas, transformaram-se em bares, lojas e restaurantes. Em inícios dos anos 1990, John conversou com Elias Rocha, o fazedor de bonecos. Perguntou sobre os seus anos na Rua do Porto. A imagem do brejo aflorou: "Sessenta e dois anos aqui... Que nem sapo, arrancou do brejo, ele morre. Se eu sair daqui, eu morro" (entrevista com Elias Rocha, 21/01/1993).

Nos anos 1990, a prefeitura deu impulso a uma nova imagem do rio como "vetor de desenvolvimento", ressaltando a importância estratégica do porto de Ártemis, próximo ao Largo dos Pescadores, e à Rua do Porto. As atenções se voltam ao potencial econômico de um rio que, desaguando no rio Tietê e, a seguir, no rio Paraná, alcança as águas da Bacia do Prata e dos países que formam o Mercosul. Em cadernos turísticos surge uma imagem de sonho do progresso: Piracicaba, "portal do Mercosul".

Nos anos 1950, muitas das pessoas que viviam do rio moravam às suas margens. Os moradores do rio Piracicaba formavam, até então, a segunda maior colônia de pescadores do estado de São Paulo. Apenas a colônia de Santos era maior (Neptune, 2003, p. 44). Nos barrancos da Rua do Porto se enfileiravam quase 2000 barcos. Mesmo em 1979, pescadores da bacia do Piracicaba captavam em média uma tonelada de peixe diariamente (Carradore; Buzetto, 2009, p. 103).

Desde 1972, ocorrem os desdobramentos do processo de "reconquista das margens do rio Piracicaba" (Otero; Souza, 2011). Na experiência de "velhos 
barranqueiros", um rio que era a "morada da vida" passa a ser projetado como um "rio de negócio". ${ }^{4}$

Às margens, ou a contrapelo de narrativas voltadas para a preservação da memória, dos fundos da memória involuntária de uma cidade, lampejam imagens: os bonecos colocados por Elias na beira do rio. Brincando de bonecos, Elias produz semelhanças entre passado e presente. Seriedade humana da brincadeira. Algo se altera. Ao lado da Casa do Povoador em vias de ser restaurada, com efeitos de uma montagem carregada de tensões, surge uma multiplicidade de bonecos povoadores.

\section{Narrativas e mimesis}

Chamam atenção as semelhanças entre narrativas de Elias sobre os bonecos e sobre os moradores da beira do rio. Ambos se transformam em personagens de dramas de um insólito cotidiano. Os bonecos são ameaçados, correm perigo.

Tacavam fogo, jogavam na água. [...] Jogavam um na água, fazia três, quatro. [...] Tacavam fogo em cinco, fazia dez no lugar. [...] Levanto de madrugada para olhar o rio. [...]. Quando vejo que não mexeram [nos bonecos] lá fico contente, alegre; quando vejo que nego tirou um eu já fico triste. Mas depois faço outro. [...] Mesma coisa fosse da minha família, meus irmãos que estão lá. (Entrevista com Elias Rocha, 21/01/1993).

Devido às malvadezas contra os bonecos, Elias os levou para o outro lado do rio, "o lado de lá", na mata próxima às ruínas de um velho engenho. Mesmo assim, as pessoas jogavam os bonecos na água e os incendiavam. Elias persistiu.

As enchentes levavam os bonecos? "Não, não leva. Alguns desbarrancam, mas, depois da enchente, a gente vai lá, arruma outra roupa, põe nele e ergue ele outra vez." O pesquisador insiste: "Mas o senhor não chegou a perder boneco por causa de enchente?" A resposta vem com ênfase: "Não! Arrancam, aproveitam a ocasião. Levam embora, jogam na água só pra ver rodar, mas [o

4 O termo "morada da vida" se inspira no título de um livro de Beatriz Heredia (1980) e o termo "rio de negócio" se inspira na discussão de José de Souza Martins (1991) sobre "terra de negócio". 
boneco] não sai de lá, está enfincado mais de meio metro. Está bem estaqueado, não sai de lá!"

Há semelhanças entre essas narrativas sobre os bonecos e as que Elias conta sobre si mesmo e sobre outros barranqueiros. Aquilo que ele diz sobre os bonecos ("não sai de lá", "fica lá") também é dito sobre si ("não saio daqui", "nada me tira daqui"). Ao entrar na cozinha de sua casa, Elias comenta: "O rio já chegou até aqui, ó [ele indica na parede a marca da enchente]. Mas nada me tira daqui. Eu até gosto de enchente."

Mas, em épocas de enchentes, é preciso se precaver. "Tem que fechar a porta. Senão a prefeitura vem e leva a mudança da gente. [...] Tem que enganar eles, senão eles levam a mudança da gente. [...] Leva no ginásio, escola... qualquer lugar."

No fundo de seu quintal, Elias diz: "Quando a prefeitura vem eu fico escondido nesse banheirinho aqui atrás esperando eles ir embora. [...] Nem a rainha da Inglaterra tira eu daqui."

Os seus parentes também não saem. “O meu irmão... [...] Piranha é o nome dele, não sai. [...] Nunca saiu. Minha irmã [...] não sai nem a pau. Saiu uma vez, voltou." Elias conta que quando a sua irmã foi para o Mato Grosso, na única vez em que saiu, ela ficou muda, ficou doente. Quando voltou, ela disse que nunca mais sairia.

Elias diz que o seu vizinho, chamado Lalo, também não sai. A recepcionista da Casa do Povoador já havia me dito que a casa de Lalo era considerada a "segunda mais antiga de Piracicaba". Elias se anima: "Fala pra ele [que você quer] comprar a casa dele. Vê se ele vende! Pode trocar, nem que seja por todas essas mansão. Pra mim também. [...] Se eu puder ser enterrado no barranco do rio, era bom". Na entrada da casa de Lalo, observa-se uma placa improvisada: "Vende-se minhoca."

Em matéria publicada a respeito da lendária enchente de 1929, o jornalista Cecílio Elias Netto (2015) evoca um estado de espírito:

O notável nas enchentes do rio Piracicaba era o comportamento dos moradores da Rua do Porto, pescadores em sua grande maioria. Eles se recusavam a deixar suas casas, mesmo quando as águas entravam pelas janelas. A tragédia chegava a ser atração também turística pelo quase inacreditável: pescadores dormindo em seus botes dentro de suas próprias casas. 
Por meio de sua arte, um artesão de bonecos se surpreende ao reconhecer semelhanças dos artefatos com barranqueiros, moradores da Rua do Porto. Ao mesmo tempo chama atenção a propensão do artesão e de outros moradores a se comportarem semelhantemente aos bonecos. Assim se produz um circuito mimético energizando uns e outros, bonecos e moradores. Ambos se "recusam" a sair dos barrancos do rio.

\section{Circuito mimético}

Num artigo acima mencionado (Dawsey, 2012), um dos autores reproduziu uma figura elaborada por Richard Schechner (1988, p. 190) a partir de suas conversas com Victor Turner. Trata-se da chamada infinity loop, uma figura de oito deitado (ou signo do infinito) atravessada ao meio por uma linha reta.

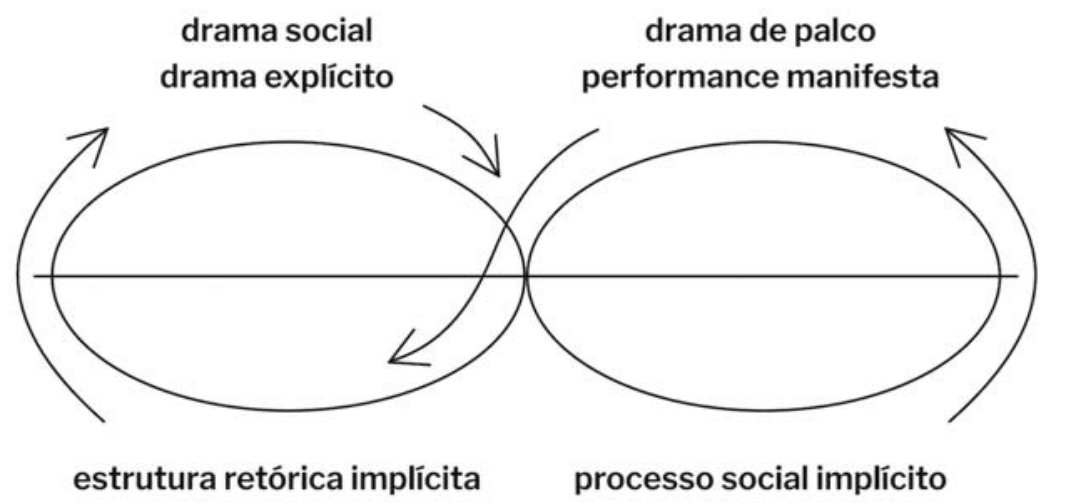

À esquerda, a esfera do drama social, subdividida em áreas de drama explícito (acima da linha) e estrutura retórica implícita (abaixo). À direita, a esfera do drama estético (de palco), repartida em regiões de performance manifesta (acima da linha) e processo social implícito (abaixo). Flechas indicam as forças das esferas em movimento. Trata-se de um processo de espelhamento interativo, matricial e "mágico", diz Turner (1985, p. 300-301). Se como espelhos mágicos dramas estéticos e rituais espelham a vida social, dramas sociais também 
espelham formas estéticas. Pessoas, que se revelam como personae, performatizam as suas vidas.

Neste ensaio, partindo do diagrama de Schechner, propõe-se um circuito mimético:

\section{CIRCUITO MIMÉTICO}

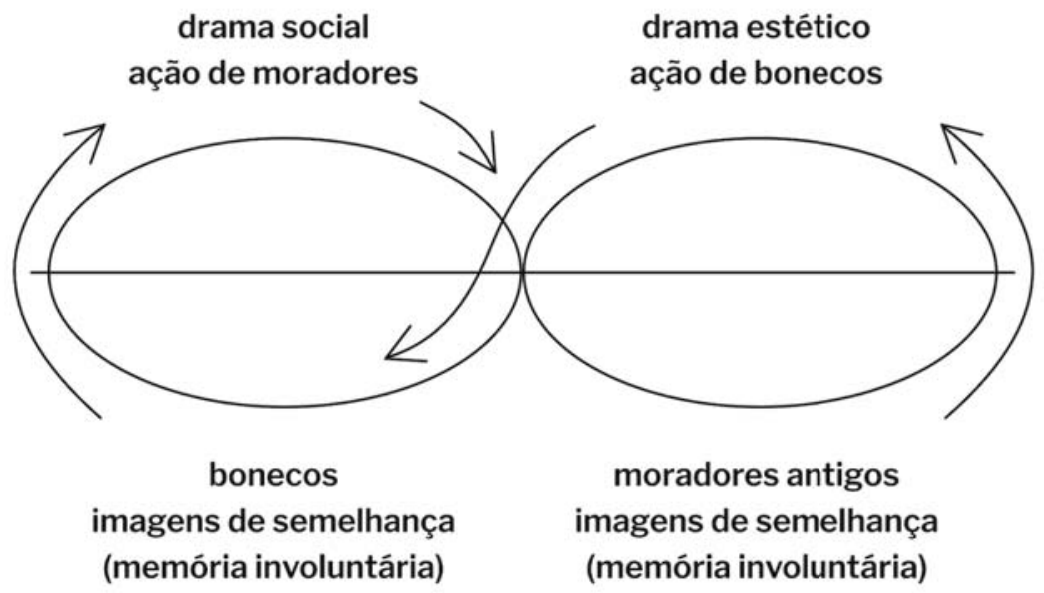

À esquerda, a esfera do drama social, subdividida em áreas de ação de moradores (acima da linha) e bonecos que aparecem como imagens de semelhança (abaixo). À direita, a esfera do drama estético (de palco), repartida em regiões de ação de bonecos (acima da linha) e moradores antigos que surgem como imagens de semelhança (abaixo). Flechas indicam a direção da ação mimética envolvendo o reconhecimento ou produção de semelhanças. Em ambas as esferas as imagens de semelhança abaixo da linha se alojam possivelmente na memória involuntária.

Para fins de análise, iniciamos com o drama de moradores, na esfera da esquerda acima da linha. Em sua ação de não sair da Rua do Porto, num momento de perigo, irrompem imagens de moradores antigos, "velhos barranqueiros", imagens de mães, pais, parentes e vizinhos que já faleceram (esfera da direita abaixo da linha). Tais imagens lampejam em forma dos bonecos de Elias 
que, por sua vez, tornam-se personagens de dramas (esfera da direita acima da linha) nos quais, embora sendo incendiados, afogados, e maltratados, também se "recusam" a sair das margens do rio. Recusam-se a sair de cena. Provocam. Como pessoas, bonecos são vistos e (des)tratados. Evocam semelhanças com outras personagens, que aos bonecos se assemelham: os moradores em seus dramas diários na Rua do Porto. Transformam-se em imagens de semelhança (esfera da esquerda abaixo da linha). Imagens viscerais. Possivelmente se alojam na memória involuntária. Ao mesmo tempo que bonecos podem ser vistos como sendo semelhantes a moradores antigos (esfera da direita), moradores se assemelham aos bonecos (esfera da esquerda).

Semelhantes a antepassados ou moradores que já morreram, bonecos entram em relações, aqui e agora, com moradores que se tornam semelhantes aos bonecos. A ação de Elias de povoar os barrancos do rio retorna com a força de um campo energizado formado por barranqueiros e bonecos revitalizando os próprios barranqueiros em sua determinação de não sair da Rua do Porto. A arte ganha vida. Bonecos também se revelam como pessoas. ${ }^{5}$

Nesse circuito se configuram relações entre vivos e mortos, presente e passado. Os bonecos evocam ancestrais, "velhos barranqueiros", "alguns que já morreram". Manifestando a presença de uma ausência, eles vêm carregados das energias da história. Com bonecos colocados à beira do rio, no sussurro das águas, Elias busca fazer uma audição das vozes emudecidas do passado. Como imagens submersas que emergem de remoinhos do tempo, surgem os bonecos.

Segredos de um bonequeiro. Não se trata de um virtuosismo envolvendo a fabricação, a manipulação ou o uso dos bonecos, mas de uma capacidade de revelar a vida que neles, de forma assombrosa, se manifesta. Nos inícios do século XX, o pensador Edward Gordon Craig (1996, p. 160, tradução nossa) via os bonecos ou Über-marionettes no teatro como "descendentes das imagens de pedra de templos antigos". Como imagens que levam as marcas do extraordinário, tais bonecos evocam, entre outras coisas, o espírito dos mortos. ${ }^{6}$ Através dos bonecos da Rua do Porto imagens do passado, em relações de semelhança, articulam-se com o presente. O sopro dos mortos desperta os sentidos dos vivos.

5 Esta discussão, que pressupõe a agência dos bonecos, também se inspira nos escritos de Alfred Gell (1998).

6 Agradecemos a Luciana Hartmann pela indicação dessa leitura. 
A partir de um reconhecimento de semelhanças, bonecos se transformam em pessoas. Para Elias, um boneco era como uma mãe ou um pai, um avô ou uma avó, um dos antigos parentes ou vizinhos, uma figura ancestral. De acordo com o artista e artesão, embora os artefatos tivessem sido feitos por suas mãos, eles não eram "bonecos do Elias". Ao contrário, ele sim era o "Elias dos bonecos". Ao fazer os bonecos, Elias se via sendo feito ou moldado por eles. ${ }^{7}$ Afinidades, semelhanças.

Elias é um narrador. Na feitura dos bonecos, nas mãos do artesão, se detecta a arte de narrar juntando passado e presente, vivos e mortos, dando forma a uma experiência coletiva. Em 1996, após uma cirurgia na garganta, Elias perdeu a sua voz. Em 1993, ele já gaguejava. Assemelhava-se aos bonecos. A imagem que surge das mãos do artesão narrador cala fundo em seu corpo.

Há outros relatos de gente vendo os bonecos como pessoas. Mães e filhos pequenos compartilhando os seus lanches junto aos bonecos. Crianças oferecendo pedaços de bolo para os bonecos. Crianças brincando e conversando com os bonecos. Um bêbado chorando abraçado num boneco (Neptune, 2003, p. 118).

\section{Circuito da dádiva}

Elias Rocha nasceu numa chácara nas margens do rio. Em suas lembranças, o rio aparece como lugar de morada. Do rio vinham os peixes que não deixavam a sua família passar fome. Em barrancos do rio se faziam os pequenos plantios de milho, mandioca, ervas, frutas e feijão. Em 1975, quando Elias foi demitido da empresa Mausa, o rio o socorreu. Um código da dádiva, envolvendo, como diria Marcel Mauss (2003), obrigações de dar, receber e retribuir, ganha força nas relações de Elias com o rio. A frase "devo obrigação" surge como um refrão nas narrativas de Elias. A seguinte montagem de trechos de uma entrevista adquire as qualidades de um texto litúrgico:

Nasci aqui no barranco do rio, na chácara Morato. [...] Mas eu devo obrigação pro rio. Trabalhei em mecânica, não ganhava nada. Ia de noite tarrafear pra ganhar

7 Uma discussão interessante dessa perspectiva teórica se encontra no livro de Tim Ingold (2013). 
um dinheirinho pra ir ao cinema. Devo obrigação pro rio. [...] Minha religião é o rio Piracicaba. [...] Devo obrigação. [...] Minha mãe, sete filhos ela criou. Se não fosse o rio nós passava miséria. Graças a Deus [...] tinha fruta, o rio tinha peixe. Arrancava minhoca para ir ao cinema. Então devo obrigação pro rio. [...] Cada dia amo mais ainda a Rua do Porto e o rio. Devo obrigação pro rio. Minha família deve obrigação pro rio. [...] A gente cansava de trabalhar, o patrão não tinha lucro. Então era miséria. Se não era o rio nós passava fome. (Entrevista com Elias Rocha, 21/01/1993).

Por que Elias fazia os bonecos? Um circuito mimético imerso em relações de dádiva envolvendo vivos e mortos ressoa na experiência do artesão que age como quem deve obrigação ao rio. Como um remoinho de onde surge a própria dádiva da vida, tanto para os que vivem no aqui e agora quanto para os que já viveram ou ainda poderão nascer, se apresenta o rio no imaginário de Elias.

O rio adquire a natureza do sagrado.

Era rico e não sabia. Fartura de comer tinha à vontade. O rio Piracicaba nunca ficou sem peixe. Eu tenho 62 anos, nunca faltou peixe no rio. Mês de frio, mês de chuva; primavera, verão, outono, inverno; sempre tem peixe no rio. É sagrado, esse rio. (Entrevista com Elias Rocha, 21/01/1993).

Em suas trocas com o rio e com o ambiente do seu entorno, moradores tornam-se semelhantes às criaturas que ali vivem. O irmão de Elias se chama Lambari, Elias se compara a um sapo do brejo. Até anos recentes, moradores comiam as plantas e os frutos de hortas cultivadas em barrancos do rio. Bebiam de suas águas e se alimentavam dos peixes. Assemelhando-se ao rio e às suas criaturas Elias e outros barranqueiros não conseguem ver-se longe de suas margens. "Se sair daqui eu morro!" Se a força das dádivas vem, como diria Mauss (2003, p. 197), do "espírito da coisa dada", esse "espírito", diria Elias, vem principalmente das águas do rio. À sua imagem e semelhança são feitas as suas criaturas.

Ao rio Elias pertence. Ao seu cavalo, que o acompanha na coleta de sucata, ele deu o nome de Lontra - um cavalo do rio. Assim também ele entende os bonecos: ao rio pertencem. 
Confeccionados com varinhas de pescar e latinhas de minhoca, os bonecos evocam uma pesca maravilhosa. Em Mimesis and alterity, Michael Taussig (1993) chama atenção para as afinidades entre a análise benjaminiana da capacidade de produzir semelhanças e a discussão de James Frazer (1982) a respeito dos princípios de similaridade e contato, ou contágio e semelhança. Os princípios da magia simpática discutidos por Frazer, em 1890, são conhecidos: primeiro, que o semelhante produz o semelhante; e, segundo, que as coisas que estiveram em contato continuam a agir sobre as outras, mesmo à distância. Os princípios se interpenetram.

Um boneco com uma vara de pescar, que se constitui como uma imagem de semelhança, feito pelas mãos de um velho barranqueiro, torna-se capaz de mobilizar outras imagens como ele, tais como os próprios moradores, e um circuito de relações formado por elementos com quais mantém contato, incluindo varinhas, peixes e águas do rio. Um mundo de correspondências. Walter Benjamin via na mimesis um modo de comunicação com o mundo. Num universo como esse, movido por forças da mimesis, as coisas "chamam" umas às outras.

Elias lembra-se do tempo em que pegava peixe do rio com a mão. Um morador chamado "Tote" evoca a imagem de outra pescaria maravilhosa: o "bate-bunda":

Lambari eles não pescavam, ele pulava no barco. Você vinha com o barco na margem assim uns dois metros longe do barranco, pra não bater com motor, e a meia marcha. Você que vem no motor vem com uma lanterna, e quem vem na ponta vem batendo. [...] O lambari pula dentro. Nossa, como pulava! (Entrevista com “Tote”, Antônio de Pádua, 21/07/1993).

Trata-se de uma imagem fantástica, surreal. A proposição de Benjamin (1993a, p. 68) no fragmento "A caminho do planetário", em Rua de mão única, é sugestiva: o trato antigo com o cosmos cumpria-se na embriaguez. Na cena acima, batendo no fundo do bote, o pescador chama os peixes. Os peixes não são pescados, eles pulam no barco.

Na pesca dos bonecos encenada por Elias tampouco são pescados. A varinha de pescar "chama" o peixe, tanto quanto o peixe "chama" a varinha de pescar. Num universo que se forma por meio dos poderes da mimesis, varinhas de pescar transformam-se em varinhas mágicas. Elas atraem os peixes. Se na 
pesca do "bate-bunda" os peixes se apresentam como dádivas do rio ("Lambari eles não pescavam, ele pulava no barco"), na pesca de Elias os bonecos pescadores com varinhas de pescar devolvem os peixes e a vida ao rio. Melhor, bonecos pescadores com os peixes por eles atraídos constituem os contradons de um circuito da dádiva que assegura a vida do rio e dos seus moradores.

O gesto de Elias de fazer bonecos pescadores colocando-os em barrancos da Rua do Porto a partir de uma obrigação de retribuir ao rio pelas dádivas recebidas sugere um circuito da dádiva.

\section{CIRCUITO DA DÁDIVA}

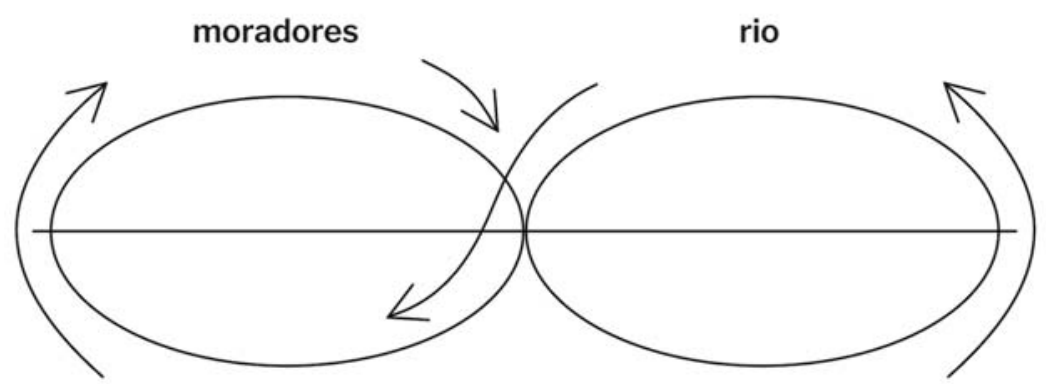

peixes e águas

bonecos

Acima da linha, os doadores e receptores de dádivas. Abaixo da linha, as dádivas. À direita, acima da linha, o rio. À esquerda, abaixo da linha, as águas e os peixes oferecidos pelo rio como dádivas aos moradores. O próprio rio se doa. Linhas de dádiva também indicam linhas de semelhança. Ao receberem águas e peixes (em forma de alimentos) moradores (à esquerda, acima da linha) tornam-se semelhantes à coisa dada. Transformam-se em seres do rio. Num momento de perigo que ameaça as suas relações de troca com o rio, um dos moradores (Elias) reconhece nos bonecos por ele confeccionados semelhanças com os próprios moradores, ou com os seus antepassados. Os bonecos são oferecidos como contradons ao rio, assegurando a continuidade do circuito da dádiva (à direita, abaixo da linha). 
No gesto de assemelharem-se a bonecos pescadores, moradores como Elias se transformam em dádivas ao rio. Os peixes por eles atraídos (em vez de pescados) agora se apresentam não como dádivas do rio para os moradores, mas como contradons dos moradores ao rio. Os peixes atraídos por bonecos são peixes vivos, ou redivivos. Inversamente, os peixes pescados por moradores, recebidos como dádivas do rio, fazem a passagem da vida à morte para que os moradores tenham vida. De modo simétrico, a vida do rio se renova num circuito da dádiva por meio de bonecos que se assemelham aos antepassados de moradores, ou seja, de moradores que também passaram da vida à morte.

Por meio dos bonecos aos quais os moradores se assemelham, no universo social e simbólico de Elias, moradores se doam ao rio. Assim sinalizam o seu pertencimento ao rio. Daí a força de sua recusa de sair da beira do rio.

Em contraste com a visão que inspira a política da prefeitura, de "reconquista das margens do rio Piracicaba" (cf. Otero; Souza, 2011), e, talvez, de conquista do próprio rio - tal como transparece em projetos voltados para fazer do rio um "vetor de desenvolvimento" - moradores como Elias buscam um saber de como se relacionar com o rio. Assemelhando-se a bonecos que se parecem com barranqueiros ancestrais renovam as relações com um rio que se revela como morada da vida.

De lugares que se afundam no tempo emergem imagens de semelhança de uma pesca maravilhosa friccionando o presente. Em meio aos cheiros de águas poluídas, das coisas apodrecidas e dos seres putrefatos, das mortandades de peixes e dos venenos despejados por fábricas e usinas, os bonecos suscitam imagens de sonhos não realizados. O tempo de agora que irrompe de um sonho narcotizante de progresso se revela com espanto.

Em Benjamin, relações de dádiva envolvem vivos e mortos. Numa imagem do passado que aflora no presente, dos fundos da memória involuntária da cidade, se produz o susto: o reconhecimento de uma semelhança. Tais como moradores aos quais se assemelham, imagens que são feitas - como será visto a seguir - dos restos e resíduos que a cidade descartou, vestidas, às vezes, nas roupas que os próprios mortos em vida usaram, friccionam o presente. No contágio das coisas e dos seres, imagens de semelhança como essas produzem a inervação dos corpos e mobilizam um corpo coletivo. As gerações do presente mantêm relações de troca com as que as precederam, com os mortos e com o mundo que thes deu a vida. 


\section{Catador}

Em Mimesis and alterity, como visto anteriormente, Michael Taussig (1993) ressalta algumas afinidades entre discussões de Frazer sobre princípios de magia e as de Benjamin sobre mimesis. Num registro inspirado por Frazer, assim como numa antropologia de feitio benjaminiano - pós-pós-frazeriana, como diria Taussig - merece atenção a interpenetração de processos de mimesis, ou de produção de semelhanças, e os de contato ou contágio.

Elias é um catador de lixo. "O maior lixeiro de Piracicaba sou eu." Em meio aos restos, às sobras e aos resíduos de materiais encontrados no rio e nas ruas da cidade, ele faz os bonecos. Em 1975, após sua demissão da empresa Mausa, ocasionada por sua participação em uma greve dos trabalhadores, Elias deu início ao seu trabalho como catador. Com uma carroça e o cavalo chamado Lontra, percorreu ruas e bairros de Piracicaba, fazendo carretos, recolhendo sucata e mantendo o sustento da família. Em fins de 1970, como visto acima, com a sucata recolhida ele começou a fazer os bonecos que habitam as margens do rio (Rocha, 2008).

Citando Charles Baudelaire, Benjamin (1985e, p. 103) ${ }^{8}$ escreve:

Temos aqui um homem: ele tem de catar pela capital os restos do dia que passou. Tudo o que a grande cidade jogou fora, tudo o que ela perdeu, tudo o que desprezou, tudo o que ela espezinhou - ele registra e coleciona. Coleta e coleciona os anais da desordem, a Cafarnaum da devassidão; separa e seleciona as coisas, fazendo uma seleção inteligente; procede como um avarento em relação a um tesouro, aferrando-se ao entulho que, nas maxilas da deusa da indústria, assumirá a forma de objetos úteis ou agradáveis.

Nos resíduos que ele coleciona, o catador de lixo revela os elementos que fazem parte da memória involuntária da cidade. Seguindo numa carroça pelas margens do rio e ruas da cidade, Elias reúne objetos levados por uma enxurrada chamada progresso.

8 Em Passagens, ver o Arquivo J68, 4 (Benjamin, 1999c, p. 349, 2006, p. 395). 
Há cumplicidades entre o catador e os seus materiais. Tanto quanto os materiais por ele reunidos, Elias e os seus vizinhos já se viram e se veem diante da ameaça de serem transformados em resíduos. Há afinidades entre moradores em risco de serem desalojados de suas casas e materiais colhidos na carroça de Elias. E há semelhanças entre os bonecos e os materiais de que são feitos: bonecos também tem uma história de serem desalojados, descartados, jogados no rio e incendiados.

Semelhança e contágio. Bonecos são feitos dos materiais que a eles se assemelham: tiras de borracha, cabos de vassoura, pedaços de pneus, chapéus descartados, sapatões esburacados, sacos de plástico arruinados, panos velhos, luvas manchadas, espuma suja, arame enferrujado, galhos de árvore decepados, roupas encontradas no lixo ou em corpos levados pelo rio. Chamam atenção as roupas que, em alguns casos, pertenceram a pessoas recentemente falecidas. E os galhos das árvores cortadas pela prefeitura.

Os materiais levam as marcas dos lugares em que foram encontrados: as margens do rio; as ruas da cidade; a chácara do Morato onde Elias nasceu; a praça em frente à Boyes, onde Elias trabalhou, conhecido como o antigo cemitério paiaguá, ou evuevi (conforme a autodenominação ameríndia); a Ponte do Caixão, onde os corpos de pessoas que morreram no rio às vezes se enroscam. Dos materiais encontrados nesses lugares são feitos os bonecos.

O trabalho do artista artesão adquire as qualidades da brincadeira e do ritual. “Aquilo está vivo pra mim. Quando estou fazendo não sou eu. É um negócio gostoso. Eu não sinto fome, sede, não fumo, nada. Quando termino eu volto a ser eu. [...] Vem às vezes um arcanjo divino pra ensinar eu fazer" (entrevista com Elias Rocha, 21/01/1993). Os restos, resíduos e sobras encontrados em ruas e rios ganham vida em forma de bonecos.

Em outro artigo, Dawsey (2012, p. 205-206) escreveu:

Com os galhos de árvores e pedaços de madeira, articulados com pregos e tiras de borracha (retiradas de câmaras-de-ar de pneus descartados), Elias monta os esqueletos dos bonecos. Com espuma e sobras de tapeçarias são moldados as pernas, os peitos, os seios, as nádegas, e partes internas dos rostos, ou máscaras. Assim se forma o corpo dos bonecos. A seguir, são vestidos com roupas, calçados e chapéus - tudo encontrado no lixo, ou doado por pessoas simpatizantes. Bonecos viram pessoas. 
O artista plástico Antonio Carlos Morelato, residente da Rua do Porto, comenta:

Quando ele pega as roupas para vestir os bonecos, ele ressuscita as pessoas. Outro dia eu vi um rapaz chorando e abraçado a um boneco, dizendo: "Esse é meu pai, esse é meu pai..." Mas era porque a roupa era do pai dele, pois o pai dele tinha morrido.

Os mortos se alojam na memória. Corpo é memória e, também, esquecimento. Dos fundos do esquecimento surgem imagens da memória involuntária. Em um ensaio sobre Franz Kafka, Benjamin (1985c, p. 162) escreve: "O que sopra dos abismos do esquecimento é uma tempestade."

\section{Índios evuevi}

Algumas imagens de semelhança suscitadas pelos bonecos possivelmente se afundam num tempo ainda mais profundo do que o dos barranqueiros da Rua do Porto, situados na margem esquerda do rio. Ou, melhor, as memórias de alguns desses barranqueiros se afundam num tempo mais profundo.

Elias Rocha nasceu na margem do rio, em 1931, na antiga chácara do Morato, na estrada do Bongue. Ele era índio - assim se apresentava. Conforme o seu relato, o seu pai era "índio" e sua mãe era "cabocla" (Rocha, 2008). Antes de trabalhar na Mausa, ele foi operário da Boyes, cujo jardim foi construído sobre um cemitério paiaguá, ou evuevi (cf. Netto, 2007). A casa onde morava se localizava ao lado do Largo dos Pescadores, na Rua Morais Barros, por onde passava a velha trilha caiapó, e que, na época dos bandeirantes, virou o "Picadão do Mato Grosso". Os antigos índios chamados paiaguás - do termo tupi-guarani significando "andarilhos do rio Paraguai" - que habitavam as margens do rio se autodenominavam evuevi, "gente do rio". Foram desalojados e dizimados por bandeirantes. Nos anos 1970, num momento em que a prefeitura dava início ao projeto de "reconquista da Rua do Porto", restaurando a Casa do Povoador, reacendendo o imaginário bandeirante, e removendo moradores, surgem os bonecos pescadores. Em momentos de perigo, imagens do passado se articulam ao presente. 
Como visto anteriormente, depois que pessoas começaram a fazer "maldades" com os bonecos, jogando-os no rio e os incendiando, Elias os levou para "o lado de lá", na mata, na margem direita, oposta à margem onde se encontrava a Casa do Povoador. Conforme uma das histórias que se contam sobre a fundação da cidade, a opção do povoador Antônio Corrêa Barbosa, em 1766, teria sido justamente a margem direita do salto, onde habitavam os índios.

Antônio Corrêa Barbosa fazia parte de um movimento bandeirante de conquista dos sertões de Cuiabá e do Mato Grosso. Piracicaba era "boca do sertão" (Perecin, 1994). Uma velha trilha caiapó transformada no "Picadão do Mato Grosso" serviu de caminho terrestre entre São Paulo e Cuiabá. O "Picadão" passava pelo porto de Piracicaba e por onde hoje se localiza o Largo dos Pescadores. Trata-se da atual Rua Morais Barros.

Na literatura sobre essa história, os paiaguás (evuevi) ganharam fama de terem sido o povo ameríndio que mais resistiu à conquista colonial portuguesa. Em 1734, deu-se início à chamada "guerra justa", uma guerra de extermínio contra os índios paiaguás e caiapós (Neme, 2009, p. 45). Há relatos de horrores, inclusive descrevendo a colocação, por soldados de tropas expedicionárias, das cabeças dos paiaguás (evuevi) mortos, espetadas em paus, nos barrancos de rios (Paiva, 1987).

Na carroça puxada pelo cavalo Lontra, Elias percorre um trajeto iluminado por imagens de semelhança. Os locais percorridos surgem como pontos numa constelação que inclui a casa de Elias situada na Morais Barros, a velha trilha caiapó que também serviu como "Picadão do Mato Grosso"; o Largo dos Pescadores onde se reuniam os barranqueiros; a área da empresa Boyes onde se localizava o cemitério paiaguá (evuevi); a chácara do Morato onde ele nasceu de um pai índio e uma mãe cabocla; e a Ponte do Caixão onde os corpos de quem morreu no rio às vezes se enroscam. Os bonecos feitos com materiais colhidos ao longo do trajeto são colocados do "lado de lá", na mata, onde, de acordo com vários relatos, os índios viveram, onde foram dizimados e onde possivelmente suas cabeças foram espetadas em paus. Nessa geografia constituída por imagens de semelhanças, o comentário anteriormente citado do artista plástico Morelato a respeito do trabalho de Elias adquire uma qualidade alucinatória: "Quando ele pega as roupas para vestir os bonecos, ele ressuscita as pessoas." 


\section{Aberturas}

Neste ensaio procuramos realizar um estudo dos bonecos de Elias a partir do pensamento benjaminiano a respeito da mimesis. As noções de circuito mimético e circuito da dádiva, assim como a discussão das relações entre ambas constituem desdobramentos significativos.

No início do ensaio, aproveitando uma discussão realizada por Jeanne-Marie Gagnebin (1993), várias críticas ao conceito de mimesis foram abordadas. Em destaque, os seguintes juízos: 1) a mimesis produz uma ilusão acompanhada possivelmente por uma experiência de arrebatamento; 2) a mimesis pode suscitar uma forma de passividade diante do real; e 3) a mimesis pode inclusive expressar uma pulsão da morte, um desejo de dissolução do sujeito.

O conceito benjaminiano de mimesis mobilizado neste ensaio abre outras perspectivas de análise. Embora os bonecos das margens do rio possam suscitar uma espécie de encantamento, ou reencantamento do mundo, chama atenção a lucidez do ato do artista e artesão. Num gesto se produz um desvio, da Casa do Povoador para as margens do rio de moradores, vivos e mortos, que do rio fizeram a sua morada. Imagens de antigos barranqueiros e de povos ameríndios se articulam ao presente, iluminando, num momento de perigo, as ilusões produzidas não pela arte dos bonecos, mas por ações de "reconquista", ao estilo de bandeirantes redivivos, alimentadas por sonhos narcotizantes de progresso.

Em lugar da passividade, observa-se um circuito mimético em que bonecos criados à semelhança de antepassados e moradores que já faleceram entram em relações com moradores que se tornam semelhantes aos bonecos. $\mathrm{O}$ gesto de Elias de povoar as margens do rio retorna com a força de um campo energizado por bonecos e barranqueiros, fortalecendo barranqueiros em sua luta por não saírem da Rua do Porto e das proximidades com o rio a que pertencem, e com qual recriam relações de dádiva.

Por fim, embora os bonecos suscitem imagens dos mortos, seja de antigos barranqueiros, seja de povos ameríndios, chama atenção o modo como essas imagens se associam a gestos de reconhecer ou mesmo recriar a vida do rio e dos moradores que vivem às suas margens. Chama atenção o modo como os resíduos da cidade e da sua história, coletados por Elias numa carroça puxada por um cavalo chamado Lontra (ver Figura 4), ganham vida na forma dos bonecos. 


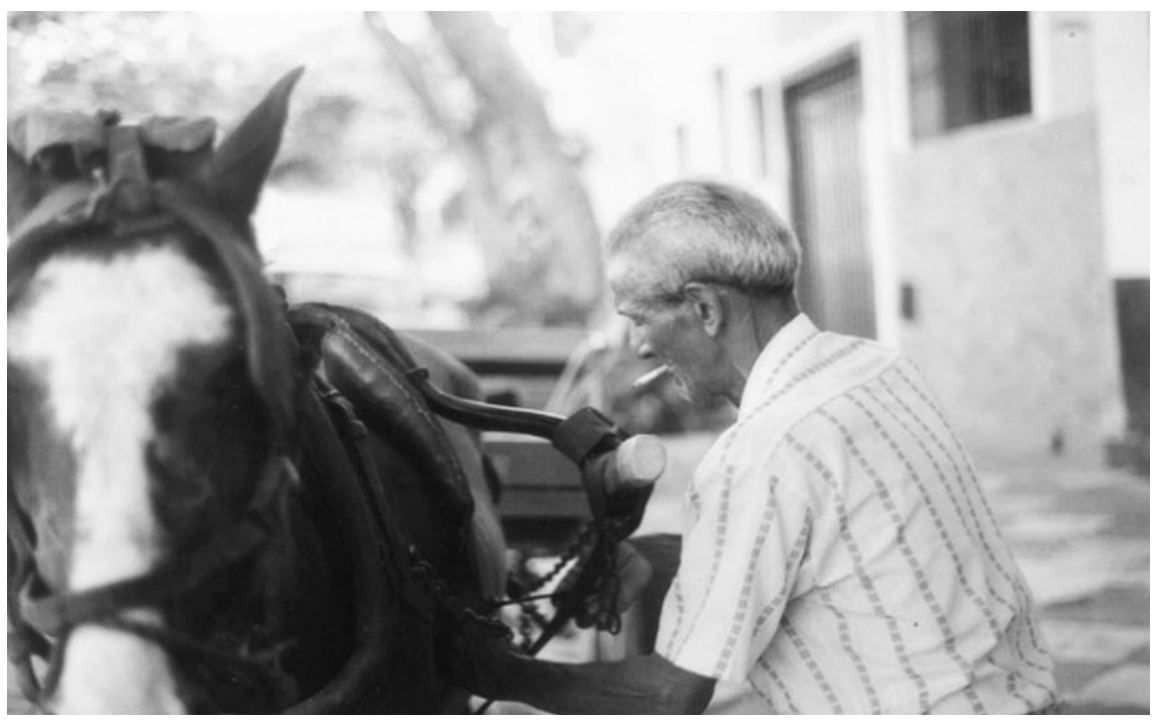

Figura 4. Elias Rocha e Lontra. Foto: John C. Dawsey.

Um adendo. Em "Infância em Berlim", Benjamin (1993b) descreve a sua expectativa, quando criança, diante da jaula da lontra, localizada nas margens internas do zoológico, à espera do instante em que aparecia a lontra que, ao romper a superfície das águas, imediatamente retornava às profundezas de onde tinha vindo. As imagens de semelhança discutidas neste ensaio têm a natureza da lontra. Num lampejo elas emergem, formando constelações.

\section{Referências}

ADORNO, T. W.; HORKHEIMER, M. Dialética do esclarecimento. Rio de Janeiro: Jorge Zahar, 1969.

BENJAMIN, W. A imagem de Proust. In: BENJAMIN, W. Obras escolhidas I: magia e técnica, arte e política. São Paulo: Brasiliense, 1985a. p. 36-49.

BENJAMIN, W. A doutrina das semelhanças. In: BENJAMIN, W. Obras escolhidas I: magia e técnica, arte e política. São Paulo: Brasiliense, 1985b. p. 108-113. 
BENJAMIN, W. Franz Kafka: a propósito do décimo aniversário de sua morte. In: BENJAMIN, W. Obras escolhidas I: magia e técnica, arte e política. São Paulo: Brasiliense, 1985c. p. 137-164.

BENJAMIN, W. Sobre o conceito da história. In: BENJAMIN, W. Obras escolhidas I: magia e técnica, arte e política. São Paulo: Brasiliense, 1985d. p. 222-232.

BENJAMIN, W. A Paris do Segundo Império em Baudelaire. In: KOTHE, F. R. (org.). Walter Benjamin. São Paulo: Ática, 1985e. p. 44-122.

BENJAMIN, W. Rua de mão única. In: BENJAMIN, W. Obras escolhidas II: rua de mão única. São Paulo: Brasiliense, 1993a. p. 9-70.

BENJAMIN, W. Infância em Berlim. In: BENJAMIN, W. Obras escolhidas II: rua de mão única. São Paulo: Brasiliense, 1993b. p. 71-142.

BENJAMIN, W. Sobre alguns temas em Baudelaire. In: BENJAMIN, W. Obras escolhidas III: Charles Baudelaire - um lírico no auge do capitalismo. São Paulo: Brasiliense, 1995. p. 103-150.

BENJAMIN, W. Doctrine of the similar. In: BENJAMIN, W. Selected writings: volume 2: 1927-1934. Cambridge: The Belknap Press of Harvard University Press, 1999a. p. 694-698.

BENJAMIN, W. On the mimetic faculty. In: BENJAMIN, W. Selected writings: volume 2: 1927-1934. Cambridge: The Belknap Press of Harvard University Press, 1999b. p. 720-722.

BEnJAMIN, W. The Arcades Project. Cambridge: The Belknap Press of Harvard University Press, 1999c.

BENJAMIN, W. Passagens. Org. Willi Bolle. Belo Horizonte: Editora UFMG; São Paulo: Imprensa Oficial do Estado de São Paulo, 2006.

CACHIONI, M.; GRIGOLETO, M. A Casa do Povoador. In: CACHIONI, M. Desenhando o patrimônio cultural de Piracicaba. Piracicaba: IPPLAP, 2011.

CARRADORE, H. P.; BUZETTO, E. Memórias do rio Piracicaba. Piracicaba: Gráfica e Editora Degaspari, 2009.

CRAIG, E. G. The actor and the Über-marionette. In: HUXLEY, M.; WITTS, N. (ed.). The twentieth-century performance reader. London: Routledge, 1996. p. 159-165.

DAWSEY, J. C. Bonecos da Rua do Porto: performance, mimesis e memória involuntária. Ilha: Revista de Antropologia, v. 13, n. 1, p. 185-219, 2012.

FRAZER, J. G. O ramo de ouro. Rio de Janeiro: Guanabara Koogan, 1982. 
FREUD, S. Beyond the pleasure principle. London: W. W. Norton, 1961.

GAGNEBIN, J.-M. Do conceito de mímesis no pensamento de Adorno e Benjamin. Perspectivas, São Paulo, v. 16, p. 67-86, 1993.

GELL, A. Art and agency: an anthropological theory. Oxford: Oxford University Press, 1998.

HEREDIA, B. A morada da vida. Rio de Janeiro: Paz e Terra, 1980.

INGOLD, T. Making: anthropology, archaeology, art and architecture. New York: Routledge, 2013.

MARTINS, J. de S. Terra de negócio e terra de trabalho. In: MARTINS, J. de S. Expropriação e violência: a questão política no campo. São Paulo: Hucitec, 1991. p. 43-60.

MAUSS, M. Ensaio sobre a dádiva. In: MAUSS, M. Sociologia e antropologia. São Paulo: Cosac \& Naify, 2003. p. 185-314.

NEME, M. A história da fundação de Piracicaba. Piracicaba: Instituto Histórico e Geográfico de Piracicaba, 2009.

NEPTUNE, N. C. Elias dos Bonecos. 2003. Dissertação (Mestrado em Artes) - Instituto de Artes, Universidade Estadual de Campinas, Campinas, 2003.

NETTO, C. E. Rua do Porto, enchente de 1929. A Província, 29 abr. 2015. Disponível em: https://www.aprovincia.com.br/memorial-piracicaba/retratos-provincia/photos/ rua-do-porto-enchente-de-1929-7250/. Acesso em: 28 maio 2012.

NETTO, C. E. Maldições sobre o Bongue (II). A Província, 7 ago. 2007. Disponível em: https://www.aprovincia.com.br/canto-cecilio/bom-dia/maldicoes-sobre-o-bongue-ii-7615/. Acesso em: 29 maio 2012.

OTERO, E. V.; BOLOGNA, S. R.; ALMEIDA, A. M. de. Parque da Rua do Porto e Área de Lazer do Trabalhador: gênese da reaproximação com o rio. In: PIRACICABA, o rio e a cidade: ações de reaproximação. Piracicaba: IPPLAP, 2011. p. 69-90.

OTERO, E. V.; SOUZA, M. B. S. D. de. A reconquista das margens do rio Piracicaba: uma reconstrução histórica à guisa de introdução. In: PIRACICABA, o rio e a cidade: ações de reaproximação. Piracicaba: IPPLAP, 2011. p. 13-46.

PAIVA, A. M. de. Os paiaguá lutaram até o fim. Diário Oficial de Mato Grosso/NDHIR, suplemento mensal, Cuiabá, ano 1, n. 8, p. 9-10, 15-16, 1987.

PERECIN, M. T. G. Piracicaba "Boca do Sertão": o porto, a paragem, a sesmaria, a povoação (1723-1767). Revista do Instituto Histórico e Geográfico de Piracicaba, Piracicaba, ano 3, n. 3, p. 11-24, 1994. 
ROCHA, M. Bonecos foram criados nos anos 70. Jornal de Piracicaba, Piracicaba, p. 4, 2 abr. 2008.

SCHECHNER, R. Selective inattention. In: SCHECHNER, R. Performance theory. New York: Routledge, 1988. p. 187-206.

TAUSSIG, M. Mimesis and alterity. New York: Routledge, 1993.

TURNER, V. On the edge of the bush. Tucson: University of Arizona Press, 1985.

Recebido: 31/01/2019 Aceito: 24/06/2019 | Received:1/31/2019 Accepted: 6/24/2019 